\title{
PRAT FERRER, J. J. y PEÑA DELGADO, A. (2015). Manual de escritura académica. Madrid: Ediciones Paraninfo, 268 pp., ISBN 978-84-28337-85-4.
}

Los estudiantes universitarios hacen uso de la escritura en sus años de formación con la finalidad de establecer una comunicación activa con la comunidad epistémica en la que han decidido realizar sus estudios de grado. En este sentido, el progresivo aprendizaje de las convenciones discursivas de los géneros adscritos al enfoque disciplinar de pertenencia le permitirá al alumno interactuar con los miembros consagrados de su entorno con escritos preliminares como el trabajo de fin de grado, el trabajo de fin de máster o la tesis doctoral, y en otros que le sucederán al final de este periplo universitario, tales como los artículos especializados, informes, manuales, etc. Estos intercambios textuales que se realizan con los escritores expertos de la disciplina tendrán como resultado la progresiva integración del estudiante dentro de su comunidad discursiva.

En este marco, el Manual de escritura académica, elaborado por Juan José Prat Ferrer y Ángel Peña Delgado, resulta ser un excelente material complementario con el que introducir al escritor novel en la composición de textos escritos en la universidad en los primeros años de transición, en los cuales el desarrollo y el consecuente dominio de la competencia escrita supone un requisito fundamental para su progreso académico. Con el objetivo último de lograr este fin, los autores de esta obra disponen a lo largo del texto una serie de recursos mediante los cuales pretenden equipar al escritor novato con herramientas válidas para que este se adentre con éxito en el reconocimiento y la producción del valor epistémico de la escritura, desde los primeros pasos de la planificación hasta la revisión final del texto.

La definición de la escritura como un proceso cognitivo es reivindicada ya desde el subtítulo de la Introducción del manual ("El proceso de escritura”), en la que se advierte que la construcción del texto está sujeta a sucesivas reelaboraciones que justifican su mejora. Este modelo, enraizado en las teorías humanistas de los años 60 y 70 (véanse Bereiter y Scardamalia 1987; Grabe y Kaplan 1996), pone el énfasis en las distintas fases de producción y en las operaciones mentales que contextualizan la construcción del texto en cada etapa de su composición: planificación, textualización y revisión. Como consecuencia del empleo de esta metodología, los estudiantes recibirán formación en un tipo de didáctica que prioriza el desarrollo del conocimiento estratégico y que tiene en 
cuenta los factores que intervienen en cada una de las fases de producción a medida que se avanza en la elaboración del texto. En este sentido, la obra reseñada resulta provechosa para resolver las dificultades planteadas en cada etapa de este proceso, cuyas pautas se explican paso a paso y con rigor. Se ofrecen para ello múltiples técnicas, estrategias, ejercicios y ejemplos que facilitan la comprensión y dotan al lector con instrumentos útiles para acometer esta tarea. Además, en esta construcción guiada del escrito académico se suceden continuamente certeros consejos y recomendaciones personales por parte de los experimentados autores, los cuales se repiten como un mantra a lo largo del manual. Estos resultan eficaces en el andamiaje de cada parte del proceso de escritura y en cada uno de los minúsculos aspectos implicados en el mismo, los cuales entrenan la capacidad de autorregulación del lector para permitirle avanzar con solidez en cada una de las fases del escrito.

La propia estructura del libro sirve de guía para la elaboración del texto. El manual se divide en dos partes claramente diferenciadas. La primera contiene los tres primeros capítulos, dedicados a la planificación y la redacción, e incide en el tercero en el modo de integrar las citas y las notas en el trabajo académico. La simetría del volumen se consigue con una segunda parte compuesta por otros tres capítulos que profundizan de manera específica en la revisión del texto y en la preparación del manuscrito final. El volumen se cierra con un sexto capítulo en el que se auxilia al estudiante sobre la siempre confusa disposición de las entradas bibliográficas en el texto académico con una minuciosa descripción de esta actividad, acompañada de claros ejemplos.

Entre los numerosos contenidos introducidos en el capítulo primero resalta la importancia concedida a la elección de un tema pertinente sobre el que elaborar el trabajo académico, la labor indispensable de realizar una exhaustiva tarea de documentación previa a la etapa de textualización, el proceso de selección del contenido y su posterior organización textual. Los autores advierten de que estos pasos deben seguir una lógica bien fundamentada con la finalidad de eludir el caos, la dispersión y la confusión en el escrito. A continuación, se describen los tipos de texto más frecuentes utilizados en el ámbito universitario y se instruye sobre la necesidad de adecuarlos al propósito establecido en la composición. El tipo de lengua y el tono se deben corresponder igualmente con la intención original que generó el texto, así como las convenciones establecidas por la disciplina a la que se dirige el escritor. Los autores del manual no solo se cuidan de guiar al lector en la construcción de la obra, sino que también le introduce en el código de prácticas honestas y éticas que gobierna el ámbito académico. 
De este modo, por ejemplo, previenen del peligro de cometer plagio cuando no se cita adecuadamente - e instrumentan cómo hacerlo de forma correcta—, de sacar la cita de contexto o de enunciar falacias o falsas argumentaciones, cuyas advertencias resultan de suma importancia para los escritores noveles que aún carecen de estos códigos y desconocen estas prácticas. Sin duda, su incorporación desde esta etapa temprana les evitará más de un disgusto a lo largo de su carrera universitaria.

El capítulo segundo propone una didáctica de la redacción centrada en dos componentes esenciales, el enunciado y el párrafo. Con este fin se lleva a cabo una profunda revisión de estos dos elementos, se explican su tamaño estándar y los errores más frecuentes que se cometen en su composición, se describen los diferentes tipos de párrafo (expositivos, argumentativos, delimitadores y de transición) y algunas nociones necesarias para mantener la coherencia interna y externa del párrafo o la relación lógica que existe entre las ideas que lo conforman. Se ofrecen también sugerencias sobre la estructuración gramatical más adecuada de los párrafos, sobre su organización y sobre las distintas maneras de enfatizar los contenidos incluidos en el trabajo académico con el fin de hacer más efectiva su composición. En el capítulo tercero se expone toda la información relativa a las citas textuales y las notas bibliográficas e informativas que un estudiante universitario debe conocer para llevar a cabo una investigación académica en este nivel. Se echa en falta en este apartado, sin embargo, una referencia expresa a las funciones retóricas que desempeñan estos elementos en el texto (SánchezJiménez 2017).

La segunda parte del libro es sustancialmente más breve en extensión que la anterior. Se abre con el capítulo cuarto, en el que se abordan de manera sistemática cuestiones relacionadas con la revisión de la estructura, el contenido y la gramática del texto. Un lugar preminente en este capítulo lo ocupa el tema de la corrección gramatical en el nivel del párrafo y del enunciado, aunque también se abordan diversos asuntos específicos relacionados con la selección léxica y con los valores estilísticos que adquieren en el discurso las distintas categorías gramaticales. A raíz de esto, se introduce una reflexión sobre la adecuación de la objetividad y la impersonalidad de los trabajos presentados en el contexto académico, como resultado de lo cual se invita al lector a adoptar estas convenciones, aunque sin renunciar por ello a la expresión de una voz propia y a su posicionamiento personal en el escrito. A continuación, se proponen algunas técnicas dirigidas a lograr la precisión gramatical en la composición relacionada con la ortografía y la puntuación. El capítulo se cierra con algunas 
pautas generales que se deben tener en cuenta si se quiere conseguir un alto grado de legibilidad en el escrito, especialmente indicadas para mantener la cohesión y la coherencia en la organización del texto.

Los dos últimos capítulos del libro ponen el foco en los aspectos más mecánicos de la composición. En el apartado quinto se alude a cuestiones relativas a la presentación final del manuscrito y la ortotipografía del texto. Esta sección del manual recoge un utilísimo listado de consulta de elementos relevantes para realizar la revisión final de los aspectos formales incluidos en el escrito, como también resultan beneficiosos los modelos propuestos para redactar las entradas bibliográficas descritas en el capítulo sexto.

A estas alturas del manual y dado el nivel crítico básico de análisis del estudiante que potencialmente accede a su consulta, el lector autodidacta -quien se ha acercado a esta obra sin armadura ni mayor bagaje en la materia que su propio ánimo por aprender- esperaría aquí un apartado que incluyera un solucionario con el que confirmar las hipótesis enunciadas en la resolución de los numerosos ejercicios que suceden a los contenidos teóricos expuestos a lo largo del libro. Este solucionario permitiría disipar las dudas surgidas sobre sus posibles respuestas al contrastarlas con las soluciones propuestas por el autor experto. No obstante, y a pesar de esta carencia, estos ejercicios son materiales que ofrecen las garantías de haber sido pilotados con éxito en las clases impartidas por los experimentados profesores Juan José Prat Ferrer y Ángel Peña Delgado en sus cursos universitarios sobre escritura académica. La reparación de esta ausencia sería, por lo tanto, el mayor acierto de una más que deseable segunda edición de este manual.

En lo que respecta a los ejemplos integrados en el texto al hilo de los contenidos teóricos, su selección resulta siempre pertinente. Tomados de textos compuestos por escritores profesionales, estos ofrecen al lector modelos probados de calidad que pueden ser utilizados como plantillas para desarrollar sus propios escritos. Los ejemplos aportan una mayor claridad al texto y contribuyen a mejorar la comprensión de los conceptos teóricos presentes en los distintos apartados del manual. Otro recurso que opera en esta misma dirección es el preciosismo del lenguaje, siempre justificado por su funcionalidad para ilustrar conceptos abstractos que de otro modo resultarían difícilmente comprensibles, como las metáforas de laberintos y túneles, el texto visto como un árbol al que podar las ramas, las pruebas como ladrillos o la cita como la levadura del pan. La inclusión de otros elementos omitidos, como diagramas y rúbricas, hubieran sido también provechosos para favorecer la comprensión de algunos temas complejos analizados en el libro. 
En conclusión, el volumen reseñado aparece en un momento histórico clave con motivo del incremento de las prácticas de escritura en la universidad en los últimos años como consecuencia de la adopción del Plan Bolonia. Por la alta calidad de sus contenidos, la exhaustiva selección de técnicas y herramientas que los autores incorporan para facilitar la intervención docente en esta materia, así como por el estilo sencillo, claro, conciso, cercano y ameno que impregna sus páginas, me atrevo a afirmar con absoluta convicción que nos encontramos ante una publicación imprescindible que resultará crucial en el trabajo de mejora de la producción escrita de los estudiantes universitarios que redactan sus textos en lengua española en cualquier disciplina académica.

David Sánchez-Jiménez

CUNY New York City College of Technology dsanchezjimenez@citytec.cuny.edu

\section{Bibliografía}

BEREITER, C. y SCARDAMALIA, M. (1987). The psychology of written composition. Hillsdale, NJ: Lawrence Erlbaum Associates.

GRABE, W. y KAPLAN, R. B. (1996). Theory and Practice of Writing: An Applied Linguistic Perspective. New York: Longman.

SÁNCHEZ-JIMÉNEZ, D. (2017). "Implicaciones de la citación en la voz del autor en el discurso académico universitario: la memoria de máster escrita en español por estudiantes españoles y filipinos”. Diálogo de la Lengua 8: 16-36. 